\title{
Urgences
}

\section{Mystérieuse cette liaison}

\section{Andrea Moorhead}

Numéro 9, 1er trimestre 1984

URI : https://id.erudit.org/iderudit/025134ar

DOI : https://doi.org/10.7202/025134ar

Aller au sommaire du numéro

Éditeur(s)

Urgences

ISSN

0226-9554 (imprimé)

1927-3924 (numérique)

Découvrir la revue

Citer ce document

Moorhead, A. (1984). Mystérieuse cette liaison. Urgences, (9), 35-42.

https://doi.org/10.7202/025134ar

Ce document est protégé par la loi sur le droit d'auteur. L'utilisation des services d'Érudit (y compris la reproduction) est assujettie à sa politique d'utilisation que vous pouvez consulter en ligne.

https://apropos.erudit.org/fr/usagers/politique-dutilisation/
Cet article est diffusé et préservé par Érudit.

Érudit est un consortium interuniversitaire sans but lucratif composé de l’Université de Montréal, l'Université Laval et l'Université du Québec à Montréal. Il a pour mission la promotion et la valorisation de la recherche. https://www.erudit.org/fr/ 
ANDREA MOORHEAD 


\section{mystérieuse cette liaison}

mystérieuse cette liaison neige et brume brouillard et fleurs la nuit en fleurs arc en ciel chutes de neige et cette longue évolution veloutée qui repand toujours mystérieuse cette liaison feuille luisante la pluie qui tombe doucement à travers les fenêtres ouvertes pouce à pouce sur un règne de nuages sur un éternel soleil, liquide, intense aube miraculeuse la fine poussière se lève à travers toute cette lumière en fleurs une liaison en brume, en neige 


\section{si douce si tendre brume}

si douce si tendre brume radieuse et terne atmosphère ce matin n'a pas de mouvement ce matin n'a ni joie ni tristesse, il s'ouvre à l'écoulement lent des heures innombrables, à l'écoulement sans visage, sans fête, sans le moindre mystère, il existe entre ce rêve dès l'aube si cher si difficile à porter et ce bonheur de nuit toujours semblable mais rose et pourpre, violet et d'un noir sans éclat.

si douce si tendre brume bleue et lente qui à travers les collines se lève, se laisse porter

pourquoi toujours à $10 \mathrm{~h} .35$

à peu près le soleil brille d'un

bleu si délicat si imprévu et frileux

et voici arrivé le jour

très sombre en son passage

très lourd et majestueux, le ciel très ouvert, la terre platte et encore anonyme terrain radieux et beau, lent et sans présage. 


\section{cendres}

comme le jour a une flamme secrète, une brume dorée, lumière étroite qui lèche qui ronge nuit pourpre, translucide terre têtue âpre

cendres dans la pluie douces molles floraison de joie sans ailes, floraison de jeunesse comme le jour a une flamme secrète, une brume dorée, lumière étroite

parole violettes qui neigent à travers mon sang aubépine et rose en fleur. 
abscence

absence pleine de lumière matin resplendit où les eaux me lavent, touchent les roses neige plus incertaine, soleil sur ma peau dans ce moment sans confins, dans ce moment sans bornes, absence noire et calme, comme un cristal qui grandit au centre des eaux, comme une lumière qui me traine, qui me forme, qui me suit. 
stages de lumière

I.

raide. terne

au commencement.

limites. les bornes.

pas de frontières.

souffle rauque.

lumineuse mais

écrasée cette main

et cette volonté

sombre,

au commencement

sans rien faire 
II.

stages de lumière: la métamorphose en velours, la préoccupation verte, jeune, le silence que toute parole impose

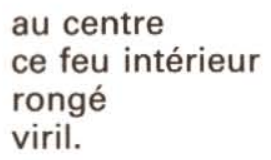

l'éclosion muette, le sang trempé. qui voyage à travers cette fragilité, lumineuse mais

écrasée au commencement. 
III.

symbole de nuit

éclose veine, pétales en floraison, sombre, sans vigile

je te porte très haut

à la hauteur sombre

au centre lumineux

mais sans feu, stages de lumière,

étincelle

souffle

sans volonté.

dorée cette vigile commencée rose depuis longtemps, cascade de métal et d'eau coulante,

en or le commencement du souffle objet précieux, protection

et le jour coule symbolique et raide, symbolique en plumes de métal

et de feu, doré, splendide 